\title{
Post-extubation non-invasive ventilation in the pediatric intensive care unit: a multicenter study
}

\author{
Juan P. Bonora, B.S. ${ }^{a}$, Judith Frydman, B.S. ${ }^{b}$, Alejandra Retta, B.S. ${ }^{c}$ and \\ Andrea Canepari, B.S. ${ }^{d}$
}

\begin{abstract}
Introduction. Extubation failure is a complication that increases morbidity and mortality. Noninvasive ventilation (NIV) has demonstrated to be effective as ventilatory support therapy. Objective. To determine the rate of postextubation NIV success and the factors associated with procedural failure or success.

Population and methods. Design: observational, retrospective, analytical, and multicenter study. All patients who required post-extubation NIV during 2014 and 2015 were included. Rescue NIV was defined as the implementation of NIV for acute respiratory failure; elective NIV was described as its implementation for prophylaxis. NIV failure was defined as the need for orotracheal intubation within the first 48 hours. The characteristics of failure and success and the types of NIV were compared, and the equipment used was assessed.

Results. RescueNIV was required in 112 children; elective NIV, in 143. The rates of success were $68.8 \%$ and $72.7 \%$, respectively. Mortality was higher among patients in whom rescue NIV failed compared to those with successful NIV. A longer length of stay and more days of invasive mechanical ventilation prior to extubation were observed in the elective NIV group. The most common diagnosis was acute lower respiratory tract infection in previously healthy children.

Conclusions. The use of post-extubation NIV may be a useful tool to prevent reintubation with invasive mechanical ventilation. Immunocompromised patients and those with neurological history had a higher rate of failure. Patients with failure tolerated less hours of NIV and had a longer length of stay in the pediatric intensive care unit.

Key words: non-invasive ventilation, pediatrics, tracheal extubation.
\end{abstract}

http: / / dx.doi.org/10.5546/ aap.2018.eng.333

d. Hospital Italiano de Buenos Aires. Autonomous City of Buenos Aires.

E-mail address:

Juan P. Bonora, B.S.: juampabon@yahoo.

com.ar

Funding:

None.

Conflict of interest:

None.

Received: 12-16-2017

Accepted: 4-19-2018

cite: Bonora JP, Frydman J, Retta A, Canepari A. Post-extubation non-invasive ventilation in the pediatric intensive care unit: a multicenter study. Arch Argent Pediatr 2018;116(5):333-339.

\section{INTRODUCTION}

Respiratory failure is one of the main reasons for admission to the pediatric intensive care unit (PICU). Children frequently require invasive of a therapeutic approach, which, despite allowing to modify the prognosis, involves life-threatening complications that extend the length of stay in the hospital. ${ }^{1}$

Post-extubation respiratory failure is a relatively common complication that remarkably increases morbidity and mortality. ${ }^{2,3}$ The rate of extubation failure among children ranges from $3 \%$ to $22 \% .{ }^{4}$ For this reason, strategies aimed at preventing reintubation in this population are required.

Non-invasive ventilation (NIV) has gained impetus as a ventilatory support therapy for pediatric patients. ${ }^{1,5}$ Its implementation/ administration reduces the use of accessory muscles, heart rate, and respiratory rate. ${ }^{1}$ The main advantage of NIV is that it prevents orotracheal intubation (OTI) and, therefore, any associated risk. ${ }^{2,3}$

Several studies have analyzed the use and effectiveness of NIV in pediatric patients. ${ }^{6-8}$ Some included all patients who required this type of ventilatory support, whereas other reports excluded post-extubation NIV from analysis because of the different characteristics of patients compared to those who had not previously received IMV. ${ }^{9}$

The bibliography on the use of post-extubation NIV in the pediatric population is scarce. ${ }^{10}$ mechanical ventilation (IMV) as part

\section{OBJECTIVE}

To determine the rate of postextubation NIV success and the factors associated with procedural failure or success.

\section{MATERIALS AND METHODS}

This was an observational, retrospective, analytical, and multicenter study. The study lasted 
2 years. All patients aged 1 month to 18 years old who required post-extubation NIV between January $1^{\text {st }}, 2014$ and December 31 $1^{\text {st }}, 2015$ in four multipurpose PICUs of tertiary care facilities were included.

Patients were extubated after a spontaneous breathing trial in accordance with the criteria in place at each facility.

Rescue NIV (rNIV) was defined as the implementation of NIV for acute respiratory failure within the first 48 hours after extubation. Respiratory failure was defined as type I or type II respiratory failure and / or upper airway obstruction. ${ }^{11}$

Elective NIV (eNIV) was defined as the implementation of NIV immediately after extubation for prophylaxis due to a potential risk for failure. eNIV was implemented in patients with prolonged IMV, ${ }^{12,13}$ prior extubation failures, weakness caused by intrinsic muscle disease, weakness of the inspiratory muscles evidenced by a reduced diaphragmatic mobility in the ultrasound or maximal inspiratory pressure below $-20 \mathrm{cmH}_{2} \mathrm{O}$, heart disease or relevant respiratory history.

The physical therapists working at each PICU recorded data every day using cards and collecting information from the medical records.

Interfaces included full-face masks, helmets, oronasal masks, nasal masks, and nasal cannulae. The interface choice depended on the patient's age and / or availability; full-face and oronasal masks were prioritized for acute respiratory failure patients, whereas nasal masks were reserved for chronic conditions.

Microprocessor-controlled ventilators with NIV-dedicated software, intermediate ventilators, and continuous flow bi-level ventilators were used. ${ }^{14}$ The ventilator was selected depending on its availability at each PICU.

Ventilation modes included pressure support ventilation, pressure-assist/control ventilation, bi-level pressure support delivered in the spontaneous or spontaneous/timed mode, and continuous positive airway pressure. The ventilation mode was chosen based on the patient's condition in an attempt to achieve the best patient-ventilator synchrony. The prevailing mode during NIV requirement was taken into consideration.

The ventilation strategy consisted in using positive end-expiratory pressure (PEEP) and fraction of inspired oxygen $\left(\mathrm{FiO}_{2}\right)$ levels necessary to achieve an oxygen saturation above $92 \%$ and the assistance pressure necessary to reach a tidal volume between 8 and $10 \mathrm{~mL} / \mathrm{kg}$. Once the therapeutic target is achieved, ventilatory parameters were progressively reduced, with rotation of the interface or periodic equipment disconnection, depending on the patient's stability in terms of clinical, blood gases, and radiological parameters, until ventilatory support was removed completely.

The following outcome measures were considered: age, weight, sex, severity score (pediatric index of mortality 2, PIM2), length of stay in the PICU (days), reason for admission to the PICU (cardiac, respiratory, neurological, postoperative period after non-cardiovascular surgery, septic shock, external injury, other), diagnosis (trauma, acute lower respiratory tract infection [ALRTI], ALRTI in a patient with sequelae [from prior comorbidities], postoperative period of a general surgery, neurosurgery, neuromuscular condition, immunocompromise, acute neurological event, non-respiratory infection, heart failure, other), reason for implementation of NIV (respiratory distress, hypoventilation, upper airway obstruction, risk for extubation failure), history (sequelae of lung disease, heart disease, neurological injury, immunocompromise, airway, digestive or liver malformations, more than one factor corresponding to the history).

The different comorbidities present in the patients were classified based on the history outcome measure, considering the classification mentioned by Feudtner et al., ${ }^{15}$ which coded patients based on the type of chronic disease.

The following parameters were monitored: partial pressure of oxygen $\left(\mathrm{PO}_{2}\right)$, saturation and partial pressure of carbon dioxide $\left(\mathrm{PCO}_{2}\right)$ prior to $\mathrm{NIV}$, and delta of pressure, $\mathrm{PEEP}, \mathrm{FiO}_{2}$ or liters of oxygen $\left(\mathrm{O}_{2}\right)$ at NIV initiation.

To measure technique effectiveness, the following outcome measures were recorded: NIV type (rescue, elective), NIV result (success, failure), hours of NIV, days of IMV prior to extubation, and mortality. NIV failure was defined as the need for endotracheal intubation within the first 48 hours in accordance with the criteria in place at each PICU. Depending on the time of failure, initial failure was defined as the need for reintubation within the first hour; early failure, as the need for reintubation from 1 to 12 hours; and late failure (> 12 hours), as the need for reintubation in any other occasion. ${ }^{5}$ The reasons for failure included 
progression of respiratory distress, hypoxemia, impaired sensorium, upper airway obstruction, hemodynamic alterations, and inability to protect the airway.

\section{Statistical analysis}

The sample was described using the median as a measure of central tendency and the 25-75 interquartile range as a measure of dispersion for numerical outcome measures; whereas, absolute count and percentage were used for categorical outcome measures. Numerical outcome measures were compared using the Mann-Whitney test and categorical outcome measures, using the $\chi^{2}$ test. A $p$ value $<0.05$ was considered statistically significant. Data were analyzed using the IBM SPSS Macintosh software, version 20.0 (IBM Corp., Armonk, NY, USA).

\section{RESULTS}

A total of 255 patients who received postextubation NIV were included. Figure 1 shows the flow chart of included patients.

The clinical and demographic characteristics of patients are described in Table 1.

The success of eNIV reached $72.7 \%$. A comparison of relevant clinical outcome measures between patients who experienced eNIV failure or success is shown in Table 2.
The success of rNIV reached $68.8 \%$. Table 3 describes the differences between patients who experienced rNIV failure or success.

The full-face mask was the most commonly used interface (106 patients, 41.6\%), followed by the oronasal mask (28.6\%), nasal cannula $(16 \%)$, nasal mask $(8.6 \%)$, nasal pillow mask $(4.3 \%)$, and helmet $(0.8 \%)$.

Also, $69 \%$ of ventilators were microprocessorcontrolled ventilators for intensive care with software to account for leakages; $29 \%$ were intermediate ventilators, and only $2 \%$ were continuous flow bi-level ventilators.

Ventilation modes included pressure support $(70.5 \%)$, pressure assist-control $(26.1 \%)$, bi-level pressure support delivered in the spontaneous / timed mode $(1.7 \%)$, and continuous positive airway pressure $(1.7 \%)$.

The total analysis of failures revealed that $60 \%$ corresponded to late failure; $20 \%$, to early failure; and $20 \%$, to initial failure. The causes of failure in the eNIV and rNIV groups were progression of respiratory distress (38.5\% and $19.7 \%$ ), upper airway obstruction $(15.4 \%$ and $36.3 \%)$, inability to protect the airway $(15.4 \%$ and $13.3 \%)$, impaired sensorium $(11.5 \%$ and $13.3 \%)$, hypoxemia $(11.5 \%$ and $6.7 \%)$, and hemodynamic alterations ( $7.7 \%$ and $10.7 \%$, respectively). Patients with neurological history and immunocompromised

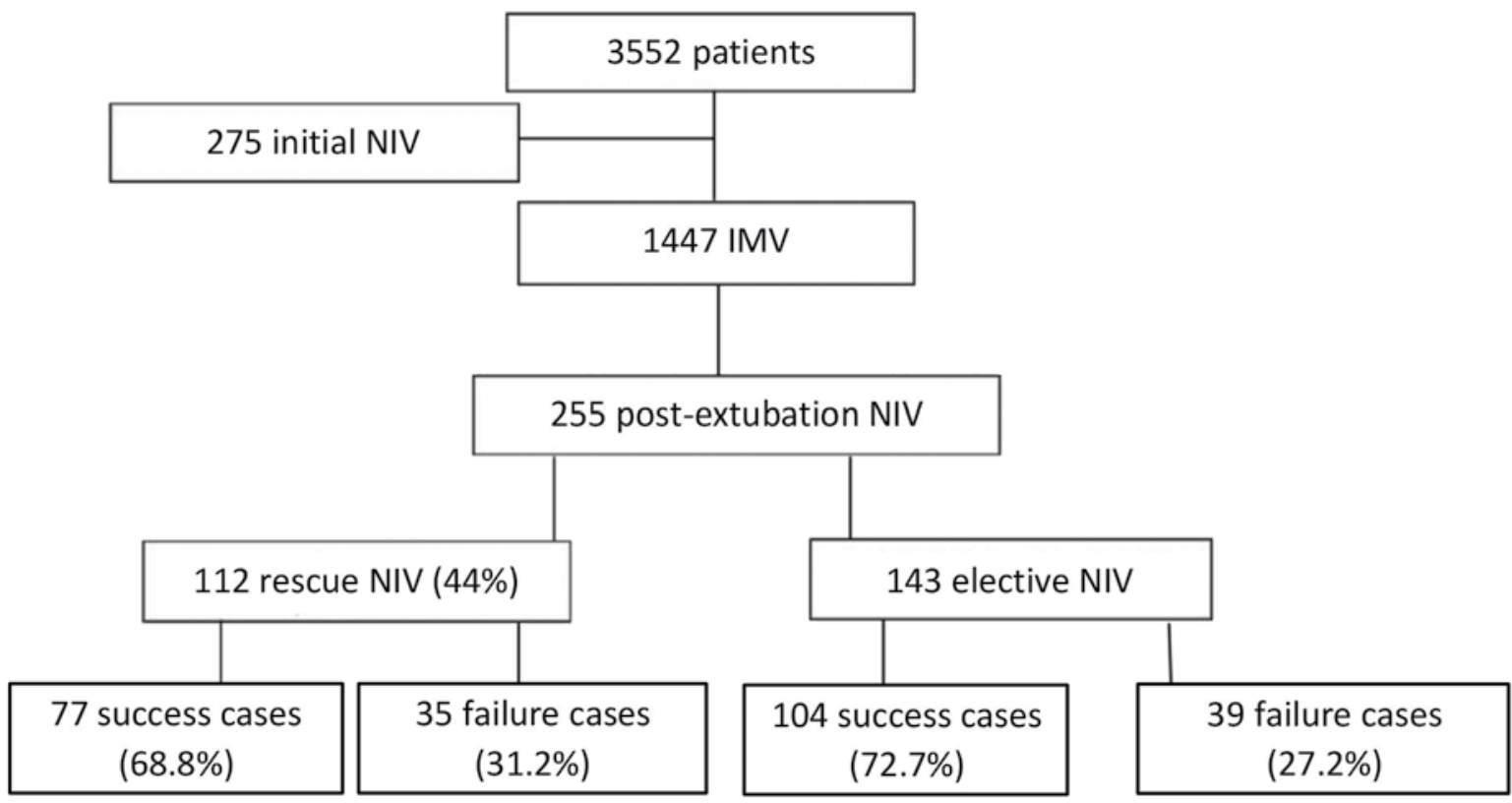

NIV: non-invasive ventilation; IMV: invasive mechanical ventilation. 
patients had a higher rate of failure $(\mathrm{n}=19 ; 41.3 \%$ and $n=13 ; 39.4 \%$, respectively) compared to those with other comorbidities, for whom the rate of failure was similar to that of the population without prior sequelae $(n=19 ; 21.7 \%)(p=0.007)$.

The overall mortality of patients with postextubation NIV was $4.4 \%$ (11 patients). Eight deaths $(5.6 \%)$ were recorded in the eNIV group; of these, 4 corresponded to those with successful eNIV, 1 with initial failure, and 3 with late failure.

Only 3 patients died in the rNIV group: 1 case of initial failure, 1 case of early failure, and 1case of late failure.

\section{DISCUSSION}

In the studied population, it was possible to avoid reimplementation of IMV in $71 \%$ of patients. Patients' median age, weight, and mortality score were 15 months, $15 \mathrm{~kg}$, and 4.8 , respectively. Besides, $48.3 \%$ of patients were girls; the most common diagnosis was respiratory infection in previously healthy children. No significant differences were observed between failure and success cases in terms of any of these outcome measures.

eNIV accounted for $56 \%$ of studied children. Gupta et al. allocated patients to receive eNIV if

TABLE 1. Demographic outcome measures

\begin{tabular}{|c|c|c|c|}
\hline Outcome measure & $\begin{array}{l}\text { Post-extubation NIV } \\
\qquad \mathrm{n}=255\end{array}$ & $\begin{array}{c}\text { Rescue NIV } \\
\mathrm{n}=112\end{array}$ & $\begin{array}{c}\text { Elective NIV } \\
\mathrm{n}=143\end{array}$ \\
\hline Age (months old), median $\left(\mathrm{Q}_{2}-\mathrm{Q}_{3}\right)$ & $15(4-72)$ & $21(4-81)$ & $12(4-66)$ \\
\hline Weight $(\mathrm{kg})$, median $\left(\mathrm{Q}_{2}-\mathrm{Q}_{3}\right)$ & $15(7-26)$ & $15(7.5-25)$ & $12,5(6,75-30)$ \\
\hline Sex, $\mathrm{n}(\%)$ & $122(48,4 \%)$ fem. & $59(52,3 \%)$ fem. & $65(45,4 \%)$ fem. \\
\hline PIM2, median $\left(Q_{2}-Q_{3}\right)$ & $4,8(1,52-10,6)$ & $4,65(1,5-10)$ & $5,6(1,54-10.8)$ \\
\hline \multicolumn{4}{|l|}{ Diagnosis, n (\%): } \\
\hline Trauma & $9(3.5 \%)$ & $7(6.3 \%)$ & $2(1.4 \%)$ \\
\hline ALRTI in previously healthy child & $70(27.5 \%)$ & $27(24.1 \%)$ & $43(30.1 \%)$ \\
\hline ALRTI in a patient with sequelae & $47(18.4 \%)$ & $14(12.5 \%)$ & $33(23.1 \%)$ \\
\hline Post-operative period of a general surgery & $41(16.1 \%)$ & $19(17 \%)$ & $22(15.4 \%)$ \\
\hline Neurosurgery & $9(3.5 \%)$ & $8(7.1 \%)$ & $1(0.7 \%)$ \\
\hline Neuromuscular condition & $9(3.5 \%)$ & $2(1.8 \%)$ & $7(4.9 \%)$ \\
\hline Immunocompromise & $13(5.1 \%)$ & $6(5.4 \%)$ & $7(4.9 \%)$ \\
\hline Acute neurological event & $11(4.3 \%)$ & $5(4.5 \%)$ & $6(4.2 \%)$ \\
\hline Non-respiratory infection & $24(9.4 \%)$ & $13(11.6 \%)$ & $11(7.7 \%)$ \\
\hline Heart failure & $3(1.2 \%)$ & - & $3(2.1 \%)$ \\
\hline Other & $19(7.5 \%)$ & $11(9.8 \%)$ & $8(5.6 \%)$ \\
\hline \multicolumn{4}{|l|}{ Reason for admission to the PICU, n (\%): } \\
\hline Cardiac & $10(3.9 \%)$ & $3(2.7 \%)$ & $7(4.9 \%)$ \\
\hline Respiratory & $114(44.7 \%)$ & $40(35.7 \%)$ & $74(51.7 \%)$ \\
\hline Neurological & $14(5.5 \%)$ & $8(7.1 \%)$ & $6(4.2 \%)$ \\
\hline Post-operative period after & & & \\
\hline non-cardiovascular surgery & $52(20.4 \%)$ & $28(25 \%)$ & $24(16.8 \%)$ \\
\hline Septic shock & $39(15.3 \%)$ & $17(15.2 \%)$ & $22(15.4 \%)$ \\
\hline External injury & $12(4.7 \%)$ & $10(8.9 \%)$ & $2(1.4 \%)$ \\
\hline Other & $14(5.5 \%)$ & $6(5.4 \%)$ & $8(5.6 \%)$ \\
\hline \multicolumn{4}{|l|}{ History, n (\%): } \\
\hline Heart disease & $17(6.7 \%)$ & $4(3.6 \%)$ & $13(9.2 \%)$ \\
\hline Sequelae of lung disease & $25(9.9 \%)$ & $12(10.9 \%)$ & $13(9.2 \%)$ \\
\hline Neurological injury & $46(18.3 \%)$ & $21(19.1 \%)$ & $25(17.6 \%)$ \\
\hline Immunocompromise & $33(13.1 \%)$ & $14(12.7 \%)$ & $19(13.4 \%)$ \\
\hline Airway, liver, digestive & & & \\
\hline malformation & $29(11.5 \%)$ & $15(13.6 \%)$ & $14(9.9 \%)$ \\
\hline More than one factor & & & \\
\hline corresponding to history & $16(5.2 \%)$ & $5(4.5 \%)$ & $8(5.6 \%)$ \\
\hline No history & $89(35.3 \%)$ & $41(37.3 \%)$ & $51(35.9 \%)$ \\
\hline \multicolumn{4}{|l|}{ Reason for implementation of NIV, $\mathrm{n}(\%)$ : } \\
\hline Respiratory distress & $75(28.2 \%)$ & $72(64.3 \%)$ & - \\
\hline Hypoventilation & $19(7.5 \%)$ & $16(14.3 \%)$ & - \\
\hline Upper airway obstruction & $24(9.4 \%)$ & $24(21.4 \%)$ & - \\
\hline Risk for extubation failure & $143(54.9 \%)$ & - & $143(100 \%)$ \\
\hline
\end{tabular}

$\mathrm{Q}_{2}-\mathrm{Q}_{3}: 25 \%-75 \%$ quartile; fem.: female; ALRTI: acute lower respiratory tract infection; PICU: pediatric intensive care unit; PIM2: severity score. 
they were at a high risk for extubation failure and if they were weaning from IMV, and achieved a success rate of $74 \% .{ }^{16}$ In addition, James et al. reached a $90 \%$ success rate with eNIV in children who were in the immediate postoperative period. ${ }^{17}$ In our study, the success of eNIV was $72.7 \%$, which was similar to that observed in comparable studies. ${ }^{9,18}$ A direct association was observed between the hours of NIV and therapeutic success, and a reverse association was noted between the length of stay in the PICU and NIV success. This evidences that patients with successful NIV remained more hours in NIV, but had a shorter stay in the PICU. Although we believe that, in our study, some children in this group would have possibly avoided OTI without
eNIV, the potential side effects of this therapy appear to be minimal.

rNIV accounted for $44 \%$ of cases. As in the study by Gupta et al., ${ }^{16}$ our results show an association between a reduced mortality and ventilatory support success. In addition, Mayordomo-Colunga et al. observed a 50\% success rate in their pilot study. ${ }^{9}$ In this group, the rate of success was $68.8 \%$, which seems logical considering that conditions are different from the eNIV group that used the therapy as prophylaxis, whereas in the rNIV group patients had signs of respiratory failure. The bibliography on the use of rNIV in the pediatric population is scarce. Studies in the adult population have not been conclusive in relation to its use. Esteban et al. demonstrated,

TABLE 2. Elective non-invasive ventilation

\begin{tabular}{|c|c|c|c|}
\hline Outcome measure & Successful $(n=104)$ & Failed $(n=39)$ & p value \\
\hline Age (months old), median $\left(\mathrm{Q}_{2}-\mathrm{Q}_{3}\right)$ & $12(5-60)$ & $15(4-85)$ & 0.85 \\
\hline Weight $(\mathrm{kg})$, median $\left(\mathrm{Q}_{2}-\mathrm{Q}_{3}\right)$ & $12(7-27.5)$ & $17(5.75-36)$ & 0.29 \\
\hline PIM2, median $\left(Q_{2}-Q_{3}\right)$ & $4.5(0.95-10.8)$ & $7.4(2.4-11.8)$ & 0.14 \\
\hline Length of stay in the PICU (days), median $\left(Q_{2}-Q_{3}\right)$ & $21(15-28)$ & $28(17-45.5)$ & 0.019 \\
\hline $\mathrm{O}_{2}$ saturation $(\%)$, median $\left(\mathrm{Q}_{2}-\mathrm{Q}_{3}\right)$ & $99(97-100)$ & $98(97-100)$ & 0.16 \\
\hline $\mathrm{PaO}_{2}(\mathrm{mmHg})$, median $\left(\mathrm{Q}_{2}-\mathrm{Q}_{3}\right)$ & $148(120-183)$ & $138(104-167.2)$ & 0.61 \\
\hline$\Delta \mathrm{P}\left(\mathrm{cmH}_{2} \mathrm{O}\right)$, median $\left(\mathrm{Q}_{2}-\mathrm{Q}_{3}\right)$ & $9(7-10)$ & $10(7.5-11)$ & 0.18 \\
\hline $\mathrm{PCO}_{2}(\mathrm{mmHg})$, median $\left(\mathrm{Q}_{2}-\mathrm{Q}_{3}\right)$ & $37(31.2-42.3)$ & $38.5(33-46.5)$ & 0.56 \\
\hline $\operatorname{PEEP}\left(\mathrm{cmH}_{2} \mathrm{O}\right)$, median $\left(\mathrm{Q}_{2}-\mathrm{Q}_{3}\right)$ & $5(5-6)$ & $6(5-7)$ & 0.12 \\
\hline $\mathrm{FiO}_{2}$, median $\left(\mathrm{Q}_{2}-\mathrm{Q}_{3}\right)$ & $0.5(0.4-0.6)$ & $0.5(0.4-0.6)$ & 0.33 \\
\hline Days of prior IMV, median $\left(Q_{2}-Q_{3}\right)$ & $10(5-15)$ & $10(5.5-22)$ & 0.47 \\
\hline Hours of NIV, median $\left(Q_{2}-Q_{3}\right)$ & $72(35.2-120)$ & $24(20-66)$ & $<0.001$ \\
\hline Mortality, $\mathrm{n}(\%)$ & $4(3.9 \%)$ & $4(11 \%)$ & 0.1 \\
\hline History, n (\%) & $62(60.2 \%)$ & $30(76.9 \%)$ & 0.062 \\
\hline
\end{tabular}

$\mathrm{Q}_{2}-\mathrm{Q}_{3}: 25 \%-75 \%$ quartile; $\mathrm{PaO}_{2}$ : partial pressure of oxygen in arterial blood; $\mathrm{PCO}_{2}$ : partial pressure of carbon dioxide; PEEP: positive end expiratory pressure; $\triangle \mathrm{P}$ : Delta of pressure; $\mathrm{FiO}_{2}$ : fraction of inspired oxygen;

PICU: pediatric intensive care unit; NIV: non-invasive ventilation; $\mathrm{O}_{2}$ : oxygen; PIM2: severity score.

TABLE 3. Rescue non-invasive ventilation

\begin{tabular}{|c|c|c|c|}
\hline Outcome measure & Successful $(n=77)$ & Failed $(n=35)$ & p value \\
\hline Age (months old), median $\left(\mathrm{Q}_{2}-\mathrm{Q}_{3}\right)$ & $30(4-84)$ & $10(3-60)$ & 0.6 \\
\hline Weight $(\mathrm{kg})$, median $\left(\mathrm{Q}_{2}-\mathrm{Q}_{3}\right)$ & $15(7.2-24.7)$ & $14(6.5-26)$ & 0.59 \\
\hline $\mathrm{PIM}_{2^{\prime}}$ median $\left(\mathrm{Q}_{2}-\mathrm{Q}_{3}\right)$ & $4.5(1.8-10)$ & $4.8(1-9.7)$ & 0.49 \\
\hline Length of stay in the PICU (days), median $\left(Q_{2}-Q_{3}\right)$ & $15.5(11-24.25)$ & $22(15-37)$ & 0.005 \\
\hline $\mathrm{O}_{2}$ saturation $(\%)$, median $\left(\mathrm{Q}_{2}-\mathrm{Q}_{3}\right)$ & $99(97-100)$ & $99(95-100)$ & 0.6 \\
\hline $\mathrm{PaO}_{2}(\mathrm{mmHg})$, median $\left(\mathrm{Q}_{2}-\mathrm{Q}_{3}\right)$ & $122.7(132.5-165.5)$ & $101.5(81.1-232.7)$ & 0.2 \\
\hline $\mathrm{PCO}_{2}(\mathrm{mmHg})$, median $\left(\mathrm{Q}_{2}-\mathrm{Q}_{3}\right)$ & $39.5(33.7-44.1)$ & $31.5(29.2-37.5)$ & 0.08 \\
\hline$\Delta \mathrm{P}\left(\mathrm{cmH}_{2} \mathrm{O}\right)$, median $\left(\mathrm{Q}_{2}-\mathrm{Q}_{3}\right)$ & $10(7-10)$ & $10(8-11)$ & 0.2 \\
\hline $\operatorname{PEEP}\left(\mathrm{cmH}_{2} \mathrm{O}\right)$, median $\left(\mathrm{Q}_{2}-\mathrm{Q}_{3}\right)$ & $5(5-6)$ & $6(5-7)$ & 0.15 \\
\hline $\mathrm{FiO}_{2^{\prime}}$ median $\left(\mathrm{Q}_{2}-\mathrm{Q}_{3}\right)$ & $0.5(0.4-0.6)$ & $0.6(0.5-0.6)$ & 0.2 \\
\hline Days of prior IMV, median $\left(Q_{2}-Q_{3}\right)$ & $5(2.5-10)$ & $6(3-9)$ & 0.33 \\
\hline Hours of NIV, median $\left(Q_{2}-Q_{3}\right)$ & $66(24-120)$ & $24(2-45)$ & $<0.001$ \\
\hline Mortality, n (\%) & - & $3(8.6 \%)$ & 0.01 \\
\hline History, n (\%) & $48(62.3 \%)$ & $23(69.7 \%)$ & 0.46 \\
\hline
\end{tabular}

$\mathrm{Q}_{2}-\mathrm{Q}_{3}: 25 \%-75 \%$ quartile; $\mathrm{PaO}_{2}$ : partial pressure of oxygen in arterial blood; $\mathrm{PCO}_{2}$ : partial pressure of carbon dioxide; PEEP: positive end expiratory pressure; $\triangle \mathrm{P}$ : Delta of pressure; $\mathrm{FiO}_{2}$ : fraction of inspired oxygen;

PICU: pediatric intensive care unit; NIV: non-invasive ventilation; $\mathrm{O}_{2}$ : oxygen; $\mathrm{PIM}_{2}$ : severity score. 
in a multicenter study, a higher mortality among patients who required rNIV compared to conventional therapy, and attributed such effect to a delay in reintubation times. ${ }^{19}$ Keenan et al. did not find differences between both groups in terms of the reintubation rate and mortality. ${ }^{20}$ Girault et al. observed that rNIV was beneficial for patients with hypercapnic ventilatory failure after extubation..$^{21}$ Dean Hess recommended caution in the use of rNIV and to prevent reintubation delays if no satisfactory response is observed in the first hour of implementation. ${ }^{22}$

In our study, $15 \%$ of patients who were admitted to the critical care unit required postextubation NIV. This is comparable to what has been described by Wolfler et al. in a study with 13 Italian intensive care units where the percentage was similar. ${ }^{23}$

The presence of a complex chronic disease seems to have an impact on the outcomes of NIV implementation..$^{15}$ In the studied population, 35\% of patients had some type of prior comorbidity. Immunocompromised patients and those with neurological sequelae showed a higher percentage of failures. Mayordomo-Colunga et al. described a higher rate of failure among patients with neurological history and attributed it to pharyngeal hypotonia and inability to protect the airway adequately. ${ }^{9}$

The analysis of failures revealed that most patients had a late failure. It has been described that a delay in reintubation increases mortality, so a late failure may increase it. ${ }^{19,20}$ However, the low mortality level observed in the studied population prevented us from establishing an association with the types of failure.

Interfaces and harnesses play a key role in NIV use. Since the introduction of the full-face mask for pediatric patients in Argentina, in 2013, there has been an increase in its demand, and, at present, it has become the preferred interface. The mask adjusts on the front, cheeks, and chin of the face, all areas where there is much subcutaneous tissue, and this has helped to reduce pressure ulcers and improve patients' comfort, especially, younger ones. Chacur et al. found that the full-face mask was more comfortable than the oronasal mask for adult patients, allowing them to use it for more time, but the authors did not find differences in the success-failure rates. ${ }^{24}$ Lemyze et al. managed to prevent intubation in adult patients with hypercapnic ventilatory failure who were receiving NIV for a prolonged time or who had facial injuries when changing from an oronasal mask to the full-face mask. ${ }^{25}$
Microprocessor-controlled ventilators are the most commonly used ones for NIV at the PICUs, which now include software to account for leakages. Faroux et al. compared, in a lab setting, the performance of 17 ventilators for NIV in pediatrics mimicking different clinical situations and patient weights. They concluded that no ventilator responded correctly to all simulation settings and had trouble working in younger children. ${ }^{26}$ The reduced respiratory effort, the high respiratory rate, and leakages in pediatric patients are a major technological challenge that needs to be resolved by advances in ventilators.

The retrospective nature of this study makes it more susceptible to biases and errors. Besides, since this is a multicenter study, there is no information on the management of each patient's underlying condition at each participating PICU. Other limitation of this study is that it did not have a randomized, controlled design and lacked a control group with patients who did not receive NIV to prevent reintubation. In this regard, patients who received eNIV may have not required any type of positive pressure, and this may have affected the end results. Lastly, there is a semantic limitation because the authors worked in four different hospitals, so each may have used different terms typical of each PICU to record NIV events.

\section{CONCLUSIONS}

The use of post-extubation NIV may be useful to prevent the reimplementation of IMV. The most common diagnosis was ALRTI in previously healthy children. Immunocompromised patients and those with neurological history had a higher rate of failure compared to those with other comorbidities, for whom the rate of failure was similar to that of the population without prior sequelae. Patients with failure tolerated less hours of NIV and had a longer length of stay in the PICU. Further studies are required to confirm the effectiveness of post-extubation NIV in the pediatric population, as well as the influence of the different interfaces and ventilators on its performance.

\section{REFERENCES}

1. Mayordomo-Colunga J, Medina A, Rey C, et al. Predictores de éxito y de fracaso en la ventilación no invasiva en la bronquiolitis aguda. An Pediatr (Barc) 2009; 70(1):34-9.

2. Epstein SK, Ciubotaru RL, Wong JB. Effect of failed extubation on the outcome of mechanical ventilation. Chest 1997; 112(1):186-92.

3. Epstein SK, Nevins ML, Chung J. Effect of unplanned extubation on outcome of mechanical ventilation. Am J RespirCrit Care Med 2000; 161(6):1912-6. 
4. KurachekS, NewthCJ, QuasneyMW, etal.Extubation failure in pediatric intensive care: a multiple-center study of risk factors and outcomes. Crit Care Med 2003; 31(11):2657-64.

5. Pons Ódena M, Piqueras Marimbaldo I, Segura Matute S, et al. Aplicación de ventilación no invasiva en pacientes postoperados cardíacos. Estudio retrospectivo. An Pediatr (Barc) 2009; 71(1):13-9.

6. Essouri S, Chevret L, Durand P, et al. Noninvasive positive pressure ventilation: Five years of experience in a pediatric intensive care unit. Pediatr Crit Care Med 2006; 7(4):329-34.

7. Yañez L, Yunge M, Emilfork $M$, et al. A prospective, randomized, controlled trial of noninvasive ventilation in pediatric acute respiratory failure. Pediatr Crit Care Med 2008; 9(5):484-9.

8. Abadesso C, Nunes P, Silvestre C, et al. Non-invasive ventilation in acute respiratory failure in children. Pediatr Rep 2012; 4(2):e16.

9. Mayordomo-Colunga J, Medina A, Rey C, et al. Non invasive ventilation after extubation in paediatric patients: a preliminary study. BMC Pediatr 2010; 10:29.

10. Demaret P, Mulder A, Loeckx I, et al. Non-invasive ventilation is useful in paediatric intensive care units if children are appropriately selected and carefully monitored. Acta Paediatr 2015; 104(9):861-71.

11. Casas Quiroga I, Contreras Zúñiga E, Zuluaga Martínez S, et al. Diagnóstico y manejo de la insuficiencia respiratoria aguda. Neumol Cir Tórax 2008; 67(1):24-33.

12. Traiber C, Piva JP, Fritsher CC, et al. Profile and consequences of children requiring prolonged mechanical ventilation in three Brazilian pediatric intensive care units. Pediatr Crit Care Med 2009; 10(3):375-80.

13. Monteverde E, Fernández A, Poterala R, et al. Characterization of pediatric patients receiving prolonged mechanical ventilation. Pediatr Crit Care Med 2011; 12(6):e287-91.

14. Scala R, Naldi M. Ventilators for Noninvasive ventilation to Treat Acute Respiratory Failure. Respir Care 2008; 53(8):1054-80.

15. Feudtner, CFeinstein JA, Zhong W, et al. Pediatric complex chronic conditions classification system version 2: updated for ICD-10 and complex medical technology dependence and transplantation. BMC Pediatr 2014; 14:199.
16. Gupta P, Kuperstock J, Hashmi S, et al. Efficacy and predictors of success of noninvasive ventilation for prevention of extubation failure in critically ill children with heart disease. Pediatr Cardiol 2013; 34(4):964-77.

17. James C, Hallewell C, James D, et al. Predicting the success of non-invasive ventilation in preventing intubation and re-intubation in the paediatric intensive care unit. Intensive Care Med 2011; 37(12):1994-2001.

18. Bonora J, Frachia D, García M, et al. Ventilación no invasiva en Cuidado Intensivo Pediátrico: cuatro años de experiencia. Arch Argent Pediatr 2011; 109(2):124-8.

19. Esteban A, Frutos-Vivar F, Ferguson N, et al. Noninvasive Positive-Pressure Ventilation for Respiratory Failure after Extubation. N Engl J Med 2004; 350(24):2452-60.

20. Keenan SP, Powers C, McCormack DG, et al. Noninvasive positive-pressure Ventilation for postextubation respiratory distress: a randomized controlled trial. JAMA 2002; 287(24):3238-44.

21. Girault C, Bubenheim M, Abroug F, et al. Noninvasive ventilation and weaning in chronichypercapnic respiratory failure: a randomized multicenter trial. Am J Resp Crit Care Med 2011; 184(6):672-9.

22. Hess D. Role of Noninvasive Ventilation in the Ventilator Discontinuation Process. Respir Care 2012; 57(10):1619-25.

23. Wolfler A, Calderini E, Iannella E, et al. Evolution of Noninvasive Mechanical Ventilation Use: A Cohort Study Among Italian PICUs. Pediatr Crit Care Med 2015; 16(5):418-27.

24. Chacur FH, Vilella Felipe LM, Fernandes CG, et al. The Total Face Mask Is More Comfortable than the Oronasal Mask in Noninvasive Ventilation but Is Not Associated with Improved Outcome. Respiration 2011; 82(5):426-30.

25. Lemyze M, Mallat J, Nigeon O, et al. Rescue Therapy by Switching to Total Face Mask After Failure of Face MaskDelivered Noninvasive Ventilation in Do-Not-Intubate Patients in Acute Respiratory Failure. Crit Care Med 2013; 41(2):481-8.

26. Faroux B, Leroux K, Desmarais G, et al. Performance of ventilators for noninvasive positive-pressure ventilation in children. Eur Resp J 2008; 31(6):1300-7. 